\title{
SÍNDROME DE BURNOUT NA MEDICINA VETERINÁRIA
}

\section{Gustavo Henrique Lima Pintoํㅗ Eduarda Rodrigues Teixeira Cassiano², Livia Fregnani de}

Almeida $^{3}$, Selene Daniela Babboni ${ }^{4}$

${ }^{1}$ Discente de Medicina Veterinária, Faculdade Anhanguera, São José dos Campos, SP.

${ }^{2}$ Discente de Medicina Veterinária, Universidade Paulista (UNIP), São José dos Campos, SP.

${ }^{3}$ Psicóloga autônoma, São José dos Campos, SP.

${ }^{4}$ Docente titular, Universidade Paulista (UNIP), São José dos Campos, SP.

DOI: $10.47094 /$ ICONRES.2021/11

\section{RESUMO}

A Síndrome de Burnout é uma condição alusiva ao fator ocupacional que interfere diretamente a saúde psicológica e física do indivíduo, gerando diversos sinais clínicos, onde a exaustão emocional é a dimensão precursora da síndrome, sendo seguida pela despersonalização, consequentemente a diminuição da realização do profissional em sua rotina de trabalho. Profissionais da área da saúde tem maior incidência nesta síndrome sendo médicos-veterinários os que representam a categoria com os índices de suicídio mais elevados, considerando a saúde mental desses profissionais acreditase que a rotina ocupacional desgastante, aliada com a predisposição do indivíduo, sejam os fatores predisponentes. A revisão de literatura teve o objetivo de descrever a Síndrome de Burnout destacando suas manifestações e inferências no que diz respeito ao médico-veterinário, profissional da saúde.

PALAVRAS-CHAVE: Profissional da saúde; estresse laboral; saúde mental.

ÁREA TEMÁTICA: Medicina Veterinária

\section{INTRODUÇÃO}

A Síndrome de Burnout é definida pela CID-11 como consequência do esgotamento mental crônico profissional (ICD-11, 2020). Em maio de 2018, a síndrome foi classificada pela Organização Mundial da Saúde como um fenômeno ocupacional, sendo incluída na Décima Primeira Revisão de Classificação Internacional de Doenças. Porém, salienta-se que a síndrome não foi categorizada como uma condição de saúde ou doença, mas especificada como um fator que influencia o estado de saúde (OPAS; OMS, 2019). 
Os profissionais da saúde estão prevalentemente relacionados à síndrome; dentre esses, os médicos-veterinários, e um dos fatores agravantes dessa profissão é a eutanásia, além das diversas responsabilidades cotidianas inerentes da prática veterinária (HANSEZ et al., 2008)

\section{METODOLOGIA}

O levantamento bibliográfico foi fundamentado a partir de buscas e análises de artigos científicos (língua portuguesa, inglesa e espanhola) obtidos nas bases de dados do Google acadêmico, PUBMED, Scientific Eletronic Library Online (SciELO). Buscou-se realizar uma revisão bibliográfica acerca da síndrome de Burnout nos profissionais de saúde enfatizando a classe da medicina veterinária, realizando um estudo descritivo.

\section{FUNDAMENTAÇÃO TEÓRICA}

O termo "Burnout", de origem inglesa, designa algo que deixou de funcionar por exaustão de energia (SILVEIRA et al, 2005). Burnout é definido por um tripé: exaustão emotiva, descaracterização e baixa realização profissional, sendo os três fatores negativos quanto a um elo saudável na profissão (CARLOTTO e PALAZZO, 2006).

O médico-veterinário se enquadra no grupo de profissionais de saúde com as manifestações clínicas da síndrome (MASLACH e LEITER, 1999), a exaustão emocional desse profissional é a primeira resposta a respeito do estresse laboral crônico, que traz consigo o desgaste físico e o esgotamento de recursos emocionais para lidar com a situação (CARLOTTO e PALAZZO, 2006). Podendo resultar em sinais físicos, como dores musculares e cefaleia, além do psíquico, como falta de paciência, ansiedade, manifestações de depressão, dificuldade no relacionamento interpessoal, perda de motivação profissional. Os médicos-veterinários estão entre os profissionais que mais sabotam a sua própria saúde mental e seu prazer de viver (MALAGRIS e FIORITO, 2006; CURY, 2016).

O DATASUS realizou uma pesquisa devido diversos relatos de suicídio e abandono de profissão por exaustão emocional, indicando que a taxa de suicídio de médicos-veterinários é de 10,6\% a frente da população geral, a frente de médicos $(5,8 \%)$ e enfermeiros $(3,6 \%)$, sendo a profissão prevalente na taxa de suicídio. Dos profissionais que desenvolvem a Síndrome as mulheres que trabalham com animais de pequenos portes são consideradas as mais predisponentes (ROLLIN, 2011; BARWALDT, 2020).

Os estudos publicados são baseados na rotina que este profissional exerce em sua rotina. Trabalham em torno de 44 a 54 horas semanais, sendo uma carga horária elevada, somando ao desequilíbrio entre a vida pessoal e profissional, sua autocrítica, são fatores que contribuem para o aumento do estresse emocional e desenvolvimento da Síndrome (MEEHAN e BRADLEY, 2007).

Outrossim, a responsabilidade do profissional, de comunicar os tutores de forma adequada 
sobre os tratamentos necessários para a cura e bem-estar do animal, e por vezes encontrando resistência do tutor, podem levar a um custo colateral da exaustão emocional (MCCULLOCH et al., 1992).

Sendo a única profissão da área da saúde que pode realizar o procedimento da eutanásia para seus pacientes, de acordo com normas éticas, o profissional tem uma sobrecarga emocional desgastante (MEEHAN e BRADLEY, 2007). A eutanásia podem envolver dilemas morais antecipatórios e futuros dilemas morais (se realizou a decisão correta, se houvesse algum procedimento que poderia ter tentado, insatisfação de ter que chegar nesse posicionamento e decisão e, explicar sobre a decisão ao tutor), o que torna um fator predisponente ao Burnout (NETT et al., 2015, FRANK, 2018).

\section{CONSIDERAÇÕES FINAIS}

A Síndrome de Burnout expõe a realidade da rotina do médico-veterinário como profissional da saúde, e as lacunas que a profissão revela quando a saúde psicológica e física é rejeitada pelo profissional e pela sociedade. As manifestações clínicas da síndrome expressam as reais condições que o médico-veterinário se enquadra, consequentemente a divergência de conectar-se consigo mesmo o que sensibiliza diretamente suas ações como profissional. Conhecer os enlaces da síndrome e suas manifestações motiva a classe veterinária a criar ações conjuntas para minimizar futuras intercorrências.

\section{PRINCIPAIS REFERÊNCIAS}

BARWALDT, E. T. et al. Reflexos da sociedade e a síndrome de Burnout na medicina veterinária: revisão de literatura. Braz. J. Hea. Rev., Curitiba, v. 3, n. 1, p. 2-14 jan./feb. 2020.

CARLOTTO, M.S.; PALAZZO, L.S. 2006. Síndrome de burnout e fatores associados: um estudo epidemiológico com professores. Cadernos de Saúde Pública, 22(5),1017-1026. Disponível em: https://www.scielosp.org/scielo.php?pid=S0102311X2006000500014\&script=sci_arttext\&tlng=en

CURY, A. 2016. Ansiedade 2- auto-controle: Como controlar o estresse e manter o equilíbrio. Benvirá, São Paulo (SP), BR.

FRANK, A. C. Síndrome de burnout na Medicina Veterinária. BOLETIM Apamvet, 2018.

HANSEZ, I.; SCHINS, F.; ROLLIN, F. Occupational stress, work-home interference and burnout among Belgian veterinary practitioners. Ir Vet J 61, 233 (2008). https://doi.org/10.1186/2046-048161-4-233

ICD-11 Implementation or Transition Guide, Geneva: World Health Organization; 2019; License: CC BY-NC-SA 3.0 IGO. Eleventh Revision, Version 09/2020.

MALAGRIS, L.E.N.; FIORITO, A. C. Avaliação do nível de stress de técnicos da área de saúde. 
Estudos de Psicologia, 23(4),391-398. 2006. Disponível em: www.scielo.br/pdf/estpsi/v23n4/ v23n4a07.pdf

MASLACH, C.; LEITER, M.P. 1999. Trabalho: fonte de prazer ou desgaste: guia para vencer o estresse na empresa. Papirus, Campinas, BR.

MCCULLOCH, M. J. et al. Ligação entre seres humanos e animais e a eutanásia - Um problema especial. In: ETTINGER, S. J. Tratado de Medicina Interna Veterinária. São Paulo: Manole, v.1, 1992, p.249-254.

MEEHAN, M.P.; BRADLEY, L. 2007. Identifying and evaluating job stress within the Australian small animal veterinary profession. Australian Veterinary Practitioner, 37(2),70-83. Disponível em:https://www.researchgate.net/profile/Michael_Meehan3/publication/43476786_Identifying_ and_evaluating_job_stress_within_the_Australian_small_animal_veterinary_profession/links/5 6e529e008ae68afa1112ae9.pdf

NETT, R. J. et al. Risk factors for suicide, attitudes toward mental illness, and practice-related stressors among US veterinarians. Journal of the American Veterinary Medical Association, 247(8), 945-955, 2015.

SAÚDE, Organização Pan Americana da; SAÚDE, Organização Mundial da. CID: Burnout é um fenômeno ocupacional. 2019. Disponível em: <https://www.paho.org/bra/index.php?option=com_co ntent\&view $=$ article\&id=5949: cidburnout-e-um-fenomeno-ocupacional\&Itemid=875>. Acesso em: 01 mar. 2021.

SILVEIRA, N.M. et al. Avaliação de burnout em uma amostra de policiais civis. Rev Psiquiatr RS. 2005; 27(2):159-63.

ROLLIN, B. E. Euthanasia, moral stress, and chronic illness in veterinary medicine. Veterinary Clinics: Small Animal Practice, 41, 651-659, 2011. 